\title{
The role of the stress regime on microseismicity induced by overpressure and cooling in geologic carbon storage
}

\author{
V. VILARRASA ${ }^{1,2}$ \\ ${ }^{1}$ Ecole Polytechnique Fédérale de Lausanne, EPFL, Lausanne, Switzerland; ${ }^{2}$ Institute of Environmental Assessment and Water \\ Research (IDAEA-CSIC), Associated Unit: Hydrogeology Group (UPC-CSIC), Barcelona, Spain
}

\begin{abstract}
Fluid injection in deep geological formations usually induces microseismicity. In particular, industrial-scale injection of $\mathrm{CO}_{2}$ may induce a large number of microseismic events. Since $\mathrm{CO}_{2}$ is likely to reach the storage formation at a lower temperature than that corresponding to the geothermal gradient, both overpressure and cooling decrease the effective stresses and may induce microseismicity. Here, we investigate the effect of the stress regime on the effective stress evolution and fracture stability when injecting cold $\mathrm{CO}_{2}$ through a horizontal well in a deep saline formation. Simulation results show that when only overpressure occurs, the vertical total stress remains practically constant, but the horizontal total stresses increase proportionally to overpressure. These hydro-mechanical stress changes result in a slight improvement in fracture stability in normal faulting stress regimes because the decrease in deviatoric stress offsets the decrease in effective stresses produced by overpressure. However, fracture stability significantly decreases in reverse faulting stress regimes because the size of the Mohr circle increases in addition to being displaced towards failure conditions. Fracture stability also decreases in strike slip stress regimes because the Mohr circle maintains its size and is shifted towards the yield surface a magnitude equal to overpressure minus the increase in the horizontal total stresses. Additionally, cooling induces a thermal stress reduction in all directions, but larger in the out-of-plane direction. This stress anisotropy causes, apart from a displacement of the Mohr circle towards the yield surface, an increase in the size of the Mohr circle. These two effects decrease fracture stability, resulting in the strike slip being the least stable stress regime when cooling occurs, followed by the reverse faulting and the normal faulting stress regimes. Thus, characterizing the stress state is crucial to determine the maximum sustainable injection pressure and maximum temperature drop to safely inject $\mathrm{CO}_{2}$.
\end{abstract}

Key words: caprock integrity, $\mathrm{CO}_{2}$ injection, induced seismicity, shear failure, thermal stresses, thermohydro-mechanical couplings

Received 1 December 2015; accepted 23 August 2016

Corresponding author: Victor Vilarrasa, Ecole Polytechnique Fédérale de Lausanne, EPFL, Route Cantonale, 1015 Lausanne, Switzerland.

Email: victor.vilarrasa@upc.edu. Tel: +34 93 4006100. Fax: +34 932045904.

Geofluids (2016) 16, 941-953

\section{INTRODUCTION}

Fluid injection in the subsurface usually induces microseismicity and, in some cases, even felt induced seismicity (National Research Council, 2013). The first reported felt induced earthquakes were triggered by wastewater injection at the Rocky Mountain Arsenal in the 1960s (Hsieh \& Bredehoeft 1981). Since then, injection activities have increased significantly, causing widespread cases of induced microseismicity and seismicity (IEAGHG, 2013). These injection activities include enhanced geothermal systems (Majer et al. 2007), geothermal energy (Evans et al. 2012), oil production (Phillips et al. 2002), seasonal storage of natural gas (Cesca et al. 2014), compressed air energy storage (Sánchez et al. 2014), wastewater injection (Ellsworth 2013) and geologic carbon storage (Rutqvist 2012).

The potential of geologic carbon storage to induce large magnitude seismic events, that is with magnitude $>4$, which could reactivate faults through which carbon dioxide $\left(\mathrm{CO}_{2}\right)$ could migrate towards the surface has been a controversial issue lately (Juanes et al. 2012; Zoback \& Gorelick 2012a,b; Vilarrasa \& Carrera 2015a). Such large events may be induced in major faults placed far from the injection well due to reservoir pressurization (Cappa \& Rutqvist 2011) or pressurization of the critically stressed 


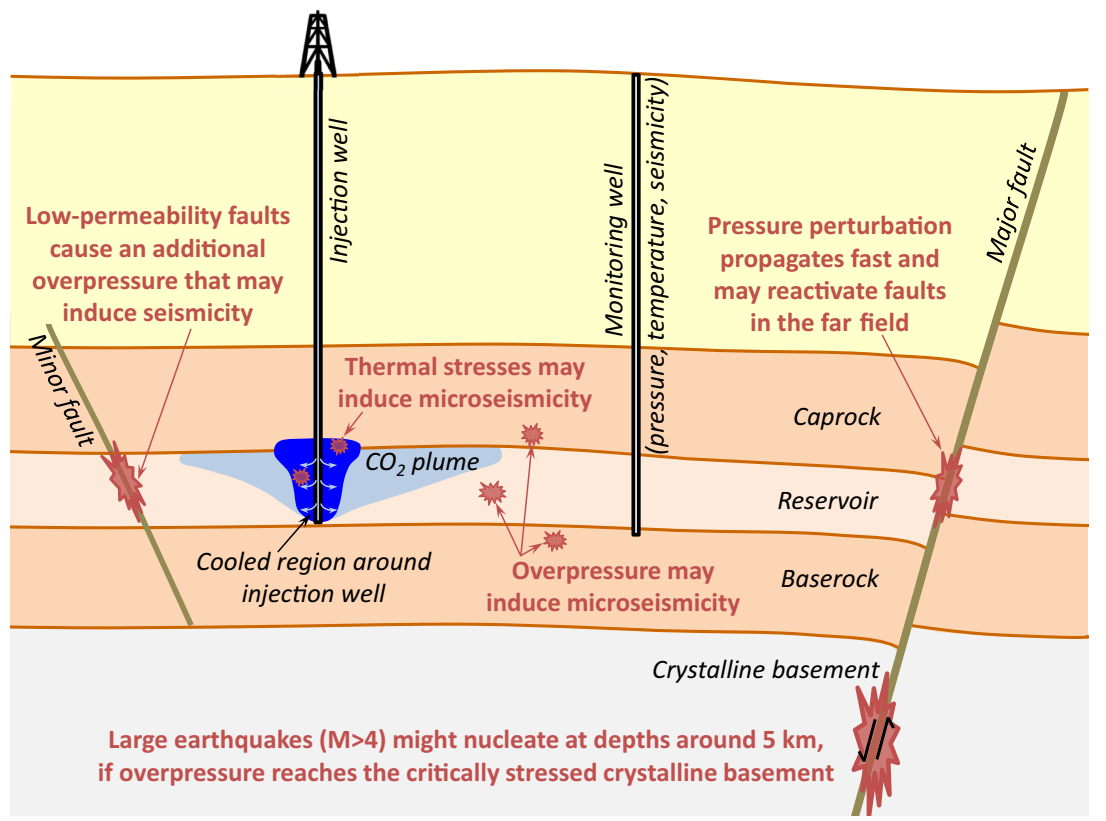

Fig. 1. Potential causes of induced microseismicity and felt induced seismicity related to geological carbon storage. crystalline basement (Zhang et al. 2013; see Fig. 1). Felt earthquakes could also be induced in undetected minor faults (Mazzoldi et al. 2012). Nevertheless, the magnitude of induced earthquakes in minor faults is unlikely to exceed magnitude 3, which may not cause damage to structures and infrastructures, but can still be felt by local population (Rinaldi et al. 2015). Despite the potential of $\mathrm{CO}_{2}$ injection to induce felt seismic events, there is an agreement that such large events can be avoided by performing a proper site characterization and pressure management (Vilarrasa \& Carrera 2015b; Zoback \& Gorelick 2015).

Apart from large magnitude induced earthquakes, induced microseismicity could also be an issue because the caprock integrity could eventually be compromised if excessive microseismic activity occurs. Figure 1 shows that in the surroundings of injection wells, apart from the effects of pressure build-up and injection-induced stresses (Segall \& Lu 2015), fracture instability may occur due to thermal stresses induced by cold $\mathrm{CO}_{2}$ injection (Vilarrasa et al. 2015). $\mathrm{CO}_{2}$ will, in general, reach the storage formation at a colder temperature than that of the rock because $\mathrm{CO}_{2}$ does not thermally equilibrate with the geothermal gradient in its way down the tubing, especially at high flow rates of injection (Paterson et al. 2008). The consequent thermal stress reduction induced by cooling brings the stress state closer to failure conditions and may cause fracture instability accompanied by induced microseismicity (de Simone et al. 2013).

The thermal stress reduction that occurs in the storage formation due to cooling is likely to yield shear failure conditions, especially in stiff reservoirs or for large temperature contrasts. However, shear failure within the reservoir may be beneficial because shear slip opens up fractures, which significantly increases their permeability (Rutqvist 2015), and thus, injectivity is enhanced. What poses a concern is whether fracture instability may occur in the caprock as well, because if fractures open up in the caprock, its sealing capacity could be negatively affected.

Caprock stability may improve if stress heterogeneity exists between the reservoir and the caprock, which is common in sedimentary basins due to the heterogeneity in geomechanical properties between different layers (Goodarzi et al. 2012; Hergert et al. 2015). If the horizontal stresses are such that the deviatoric stress is smaller in the caprock than in the reservoir, the caprock may remain stable with respect to shear failure despite the thermal stress reduction (Goodarzi et al. 2015). Simulation results have also shown a stabilizing situation when injecting cold $\mathrm{CO}_{2}$ through a vertical well because the thermal stress reduction that occurs in the vertical stress within the reservoir causes stress redistribution to satisfy stress equilibrium and displacement compatibility. This stress redistribution results in an increase of the horizontal total stresses in the lower portion of the caprock (Vilarrasa et al. 2013) that tightens the caprock in normal faulting stress regimes, that is stress regimes where the maximum principal stress is in the vertical direction, due to the resulting lower deviatoric stress that decreases the likelihood of shear failure.

On the other hand, simulation results of cold $\mathrm{CO}_{2}$ injection in strike slip stress regimes, that is when the vertical stress is the intermediate principal stress, show a decrease in caprock stability induced by cooling (Preisig \& Prévost 2011; Vilarrasa et al. 2015). Although all the studies that consider a strike slip stress regime agree that shear failure is likely to occur in the cooled region of the caprock, at least 
in critically oriented fractures, only some of them predict tensile stresses, which could create hydraulic fractures (Preisig \& Prévost 2011; Gor et al. 2013). In view of the differences in results among stress regimes, it seems necessary to investigate in detail the coupled thermo-hydro-mechanical processes that control caprock stability for each stress regime.

The aim of this study was to shed light on how caprock stability and subsequent induced microseismicity are affected when injecting cold $\mathrm{CO}_{2}$ through a horizontal well in each stress regime, that is normal faulting, strike slip and reverse faulting. We first present the governing equations of nonisothermal $\mathrm{CO}_{2}$ injection in a deformable porous media and the numerical model that we use. Then, we analyse caprock stability for each stress regime. Finally, we discuss the implications of the effect of the stress regime on the caprock stability and draw the conclusions of this study.

\section{METHODS}

We consider $\mathrm{CO}_{2}$ injection in a deep saline reservoir that is overlaid and underlain by a low permeability and high entry pressure formation that prevents $\mathrm{CO}_{2}$ from migrating upwards (Marschall et al. 2005). The injected $\mathrm{CO}_{2}$ will, in general, reach the storage formation at a colder temperature than that corresponding to the geothermal gradient (Vilarrasa et al. 2014). Thus, to solve this coupled thermohydro-mechanical problem of cold $\mathrm{CO}_{2}$ injection in a brine saturated deformable porous media, mass conservation of each phase, energy balance and momentum balance should be solved simultaneously.

Mass conservation of both $\mathrm{CO}_{2}$ and water can be written as (Bear 1972),

$\frac{\partial\left(\varphi S_{\alpha} \rho_{\alpha}\right)}{\partial t}+\nabla \cdot\left(\rho_{\alpha} \mathbf{q}_{\alpha}\right)=r_{\alpha} \quad \alpha=c, w$

where $\varphi\left[\mathrm{L}^{3} \mathrm{~L}^{-3}\right]$ is porosity, $S_{\alpha}[-]$ is saturation of the $\alpha$-phase, $\rho_{\alpha}\left[\mathrm{M} \mathrm{L}^{-3}\right]$ is density, $t[\mathrm{~T}]$ is time, $\mathbf{q}_{\alpha}\left[\mathrm{L}^{3} \mathrm{~L}^{-2}\right.$ $\left.\mathrm{T}^{-1}\right]$ is the volumetric flux, $r_{\alpha}\left[\mathrm{M} \mathrm{L}^{-3} \mathrm{~T}^{-1}\right]$ is the phase change term, that is $\mathrm{CO}_{2}$ dissolution into water and water evaporation into $\mathrm{CO}_{2}$, and $\alpha$ is either $\mathrm{CO}_{2}$ rich phase, $c$, or aqueous phase, $w$. In the numerical simulations, we neglect evaporation of water into $\mathrm{CO}_{2}$, that is $r_{w}=0$.

Momentum conservation for the fluid phases is given by Darcy's law

$\mathbf{q}_{\alpha}=-\frac{k k_{r \alpha}}{\mu_{\alpha}}\left(\nabla P_{\alpha}+\rho_{\alpha} g \nabla z\right) \quad \alpha=c, w$,

where $k\left[\mathrm{~L}^{2}\right]$ is intrinsic permeability, $k_{r \alpha}[-]$ is $\alpha$-phase relative permeability, $\mu_{\alpha}\left[\mathrm{M} \mathrm{L}^{-1} \mathrm{~T}^{-1}\right]$ is $\alpha$-phase viscosity, $P_{\alpha}\left[\mathrm{M} \mathrm{L}^{-1} \mathrm{~T}^{-2}\right]$ is $\alpha$-phase pressure, and $g\left[\mathrm{~L} \mathrm{~T}^{-2}\right]$ is gravity.
Energy conservation, taking into account the non-negligible compressibility of $\mathrm{CO}_{2}$, can be expressed as (e.g. Nield \& Bejan 2006)

$$
\begin{aligned}
& \frac{\partial\left((1-\varphi) \rho_{s} h_{s}+\varphi \rho_{w} S_{w} h_{w}+\varphi \rho_{c} S_{c} h_{c}\right)}{\partial t} \\
& -\varphi S_{c} \frac{D P_{c}}{D t}+\nabla \cdot\left(-\lambda \nabla T+\rho_{w} h_{w} \mathbf{q}_{w}+\rho_{c} h_{c} \mathbf{q}_{c}\right)=0,
\end{aligned}
$$

where $\rho_{s}\left[\mathrm{M} \mathrm{L}^{-3}\right]$ is solid density, $\boldsymbol{h}_{\alpha}\left[\mathrm{L}^{2} \mathrm{~T}^{-2}\right]$ is enthalpy of $\alpha$-phase $\left(\alpha=c, w, s ; s\right.$ for solid), $\lambda\left[\mathrm{M} \mathrm{L} \mathrm{T}^{-3} \Theta\right]$ is thermal conductivity, and $T[\Theta]$ is temperature. We assume local thermal equilibrium of all phases at every point.

The momentum balance of the solid phase is reduced to the equilibrium of stresses if inertial terms are neglected

$\nabla \cdot \boldsymbol{\sigma}+\mathbf{b}=\mathbf{0}$

where $\boldsymbol{\sigma}\left[\mathrm{M} \mathrm{L}^{-1} \mathrm{~T}^{-2}\right]$ is the stress tensor and $\mathbf{b}\left[\mathrm{M} \mathrm{L}^{-2}\right.$ $\left.\mathrm{T}^{-2}\right]$ is the body forces vector.

We assume that the rocks behave elastically, so thermoporoelastic strain can be calculated as a function of total stress, overpressure and temperature, as (Segall \& Fitzgerald 1998)

$\boldsymbol{\varepsilon}=\frac{1+v}{E} \boldsymbol{\sigma}-\frac{3 v}{E} \sigma_{m} \mathbf{I}-\alpha_{b} \frac{1-2 v}{E} \Delta P \mathbf{I}-\alpha_{T} \Delta T \mathbf{I}$,

where $\varepsilon\left[\mathrm{L} \mathrm{L} \mathrm{L}^{-1}\right]$ is the strain tensor, $\sigma_{m}=\left(\sigma_{1}+\sigma_{2}+\right.$ $\left.\sigma_{3}\right) / 3$. $\left[\mathrm{M} \mathrm{L}^{-1} \mathrm{~T}^{-2}\right]$ is mean stress, $\sigma_{i}, i=1,2,3$, are the principal stresses, I [-] is the identity matrix,

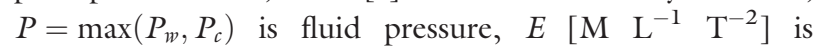
Young's modulus, $v[-]$ is Poisson ratio, $\alpha_{b}$ is the Biot coefficient (assumed equal to 1 ), and $\alpha_{T}\left[\Theta^{-1}\right]$ is thermal expansion coefficient of the porous medium. The sign criterion of geomechanics is adopted, that is stress and strain are positive in compression and negative in extension.

To assess how close the stress state is to shear failure conditions, we calculate the mobilized friction angle, adopting the Mohr-Coulomb failure criterion, as

$\phi_{\mathrm{mob}}=\arctan \left(\frac{\tau}{\sigma_{n}^{\prime}}\right)$,

where $\tau\left[\mathrm{M} \mathrm{L}^{-1} \mathrm{~T}^{-2}\right]$ is the tangential stress and $\sigma_{n}^{\prime}[\mathrm{M}$ $\left.\mathrm{L}^{-1} \mathrm{~T}^{-2}\right]$ is the normal effective stress acting on a fracture. This definition of the mobilized friction angle conservatively assumes that a cohesionless critically oriented fracture could exist at every point. If the mobilized friction angle equals the actual fracture strength, the fracture undergoes shear failure and the slip could induce a microseismic event. We assume that the actual friction angle of fractures equals $30^{\circ}$ (Byerlee 1978).

Figure 2 illustrates the geometry and initial and boundary conditions of the considered model. A 20-m-thick storage formation, like the one at In Salah, Algeria (Rutqvist 2012 ), is placed at a depth of $1.5 \mathrm{~km} . \mathrm{CO}_{2}$ is injected through a horizontal well located at the middle of the 


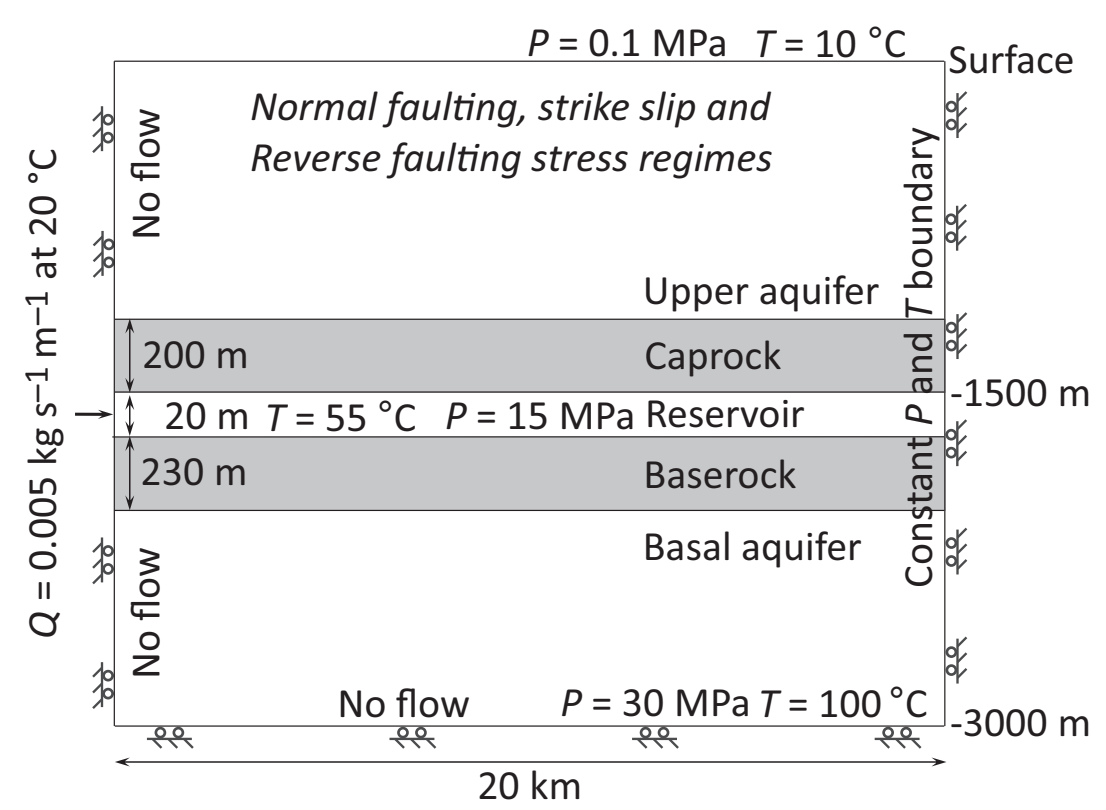

Fig. 2. Schematic representation of the model set-up, indicating the geometry and initial and boundary conditions. reservoir thickness, that is $10 \mathrm{~m}$ below the caprock. Making use of symmetry in the direction of the axis of the horizontal well, we model a $2 \mathrm{D}$ plane strain section. In fact, we only need to model half of the $2 \mathrm{D}$ section owing to the symmetry at the vertical plane that passes through the centre of the injection well. Table 1 includes the thermohydro-mechanical properties of all the rock types considered in the model.

Initially, fluid pressure is in hydrostatic conditions and the temperature follows a linear distribution, with $10^{\circ} \mathrm{C}$ at the surface and a geothermal gradient of $30^{\circ} \mathrm{C} \mathrm{km}^{-1}$. Thus, the initial reservoir temperature is of $55^{\circ} \mathrm{C}$. We

Table 1 Material properties used in the thermo-hydro-mechanical analysis of cold $\mathrm{CO}_{2}$ injection.

\begin{tabular}{|c|c|c|c|}
\hline Property & Reservoir & $\begin{array}{l}\text { Caprock and } \\
\text { baserock }\end{array}$ & $\begin{array}{l}\text { Upper and } \\
\text { basal aquifers }\end{array}$ \\
\hline Permeability, $k\left(\mathrm{~m}^{2}\right)$ & $10^{-13}$ & $10^{-17}$ & $10^{-14}$ \\
\hline $\begin{array}{l}\text { Relative water } \\
\text { permeability, } k_{r w}(-)\end{array}$ & $S_{w}^{3}$ & $S_{w}^{6}$ & $S_{w}^{3}$ \\
\hline $\begin{array}{l}\text { Relative } \mathrm{CO}_{2} \\
\text { permeability, } k_{r c}(-)\end{array}$ & $S_{c}^{3}$ & $S_{c}^{6}$ & $S_{c}^{3}$ \\
\hline $\begin{array}{l}\text { Gas entry pressure, } \\
P_{0}(\mathrm{MPa})\end{array}$ & 0.02 & 1.0 & 0.02 \\
\hline van Genuchten $m(-)$ & 0.8 & 0.5 & 0.8 \\
\hline Porosity, $\varphi(-)$ & 0.1 & 0.01 & 0.1 \\
\hline $\begin{array}{l}\text { Young's modulus, } \\
E(\mathrm{GPa})\end{array}$ & 4.0 & 5.0 & 15.0 \\
\hline Poisson ratio, $v(-)$ & 0.3 & 0.3 & 0.3 \\
\hline $\begin{array}{l}\text { Thermal conductivity, } \\
\lambda\left(\mathrm{W} \mathrm{m}^{-1} \mathrm{~K}^{-1}\right)\end{array}$ & 2.4 & 1.5 & 2.4 \\
\hline $\begin{array}{l}\text { Solid specific heat } \\
\text { capacity, } c_{p}\left(\mathrm{~J} \mathrm{~kg}^{-1} \mathrm{~K}^{-1}\right)\end{array}$ & 874 & 874 & 874 \\
\hline $\begin{array}{l}\text { Linear thermal expansion } \\
\text { coefficient, } \alpha_{T}\left({ }^{\circ} \mathrm{C}^{-1}\right)\end{array}$ & $1.5 \cdot 10^{-5}$ & $1.5 \cdot 10^{-5}$ & $1.5 \cdot 10^{-5}$ \\
\hline
\end{tabular}

consider three different initial stress states corresponding to the three stress regimes, that is normal faulting, strike slip and reverse faulting. In all cases, the vertical stress is given by the weight of the overburden, which equals $24 \mathrm{MPa} \mathrm{km}^{-1}$. In the normal faulting stress regime, the two horizontal principal stresses are the same and equal to $0.68 \sigma_{v}$. In the strike slip stress regime, the maximum and minimum horizontal principal stresses have a gradient of $1.03 \sigma_{v}$ and $0.70 \sigma_{v}$, respectively. In the reverse faulting stress regime, both horizontal principal stresses have a stress gradient of $1.65 \sigma_{v}$. The horizontal stress gradients were chosen to yield the same initial mobilized friction angle, equal to $21.5^{\circ}$, in the three stress regimes.

$\mathrm{CO}_{2}$ is injected at a rate of $0.005 \mathrm{~kg} \mathrm{sec}^{-1} \mathrm{~m}^{-1}$, but due to the symmetry of the problem, the injection rate is actually $0.01 \mathrm{~kg} \mathrm{sec}^{-1} \mathrm{~m}^{-1}$. $\mathrm{CO}_{2}$ is injected at $20^{\circ} \mathrm{C}$ during 5 years, and in order to evaluate thermo-mechanical effects, we also perform isothermal simulations in which $\mathrm{CO}_{2}$ is injected in thermal equilibrium with the storage formation. Fluid pressure and temperature are kept constant at the outer boundary following a hydrostatic profile and the geothermal gradient, respectively. At the top boundary, which coincides with the surface, fluid pressure equals the atmospheric pressure and temperature is assumed to have a mean surface temperature of $10^{\circ} \mathrm{C}$. The other two boundaries, that is the bottom boundary and the vertical symmetry boundary where $\mathrm{CO}_{2}$ is injected, are no flow boundaries. The mechanical boundary conditions are a constant overburden equal to the atmospheric pressure at the top boundary and no displacement perpendicular to the other boundaries.

This problem is numerically simulated using the finite element numerical code CODE_BRIGHT (Olivella et al. 
1994, 1996), which has been extended for simulating nonisothermal $\mathrm{CO}_{2}$ injection (Vilarrasa et al. 2013). This code solves the thermo-hydro-mechanical couplings in a fully coupled way. The mesh is made of 3400 structured quadrilateral elements. The elements in the reservoir present a shape similar to squares of $1.5 \mathrm{~m}$ by side for the $50 \mathrm{~m}$ that are closer to the injection well. Further away, the element size in the horizontal direction progressively increases up to $1500 \mathrm{~m}$ next to the outer boundary. In the caprock and baserock, the height of the elements is of $1.5 \mathrm{~m}$ next to the reservoir and progressively increases up to $35 \mathrm{~m}$ at the other end of each layer. The height of the elements of the upper and basal aquifers is of $250 \mathrm{~m}$. We verified that simulation results are not mesh dependent by performing a mesh sensitivity analysis.

\section{RESULTS}

\section{Geomechanical changes induced by cold $\mathrm{CO}_{2}$ injection}

Cold $\mathrm{CO}_{2}$ induces both overpressure and cooling. These two effects bring the stress state closer to failure conditions. If shear failure occurs in a pre-existing fracture, the planes of the fracture undergo shear slip, which is usually accompanied by a microseismic event. To investigate the effective stress evolution in different stress regimes, the total stress changes induced by overpressure and cooling need to be quantified. Since we assume that the rocks behave elastically, these stress changes will be the same regardless of the initial stress state.

Figure 3 displays the temperature distribution after 5 years of injecting $\mathrm{CO}_{2}$ at $20^{\circ} \mathrm{C}$. Close to the injection well, the temperature is the same as that of the injected $\mathrm{CO}_{2}$, but cooling becomes less pronounced as the distance to the well increases. Actually, the temperature change in the reservoir $8 \mathrm{~m}$ above the injection well is of $-19^{\circ} \mathrm{C}$ after 5 years of injection (Fig. 4). This temperature change is almost half of the one that occurs next to the well, which is of $-35^{\circ} \mathrm{C}$. The temperature change becomes even smaller in the caprock.

Cooling of the caprock occurs mainly by conduction, because its low permeability hinders $\mathrm{CO}_{2}$ flow across it. In contrast, both conduction and advection of heat take place in the reservoir. This difference in the heat transport mechanisms between the caprock and the reservoir causes an anisotropic propagation of the cooled region, with cooling advancing further horizontally than vertically. Still, cooling affects a non-negligible region of the lower portion of the caprock close to the injection well. This cooled region extends approximately $60 \mathrm{~m}$ to each side of the injection well and $20 \mathrm{~m}$ into the lower portion of the caprock.

Apart from cooling, $\mathrm{CO}_{2}$ injection induces overpressure. Figure 5 shows how overpressure evolves both in the reservoir and in the caprock for $\mathrm{CO}_{2}$ injection at $20^{\circ} \mathrm{C}$ and in thermal equilibrium with the storage formation. Overpressure reaches $5 \mathrm{MPa}$ in the reservoir after 5 years of injection. This value is within the range of overpressure that can be expected in industrial-scale $\mathrm{CO}_{2}$ storage projects. For example, the overpressure at In Salah, Algeria, where injection was performed under fracturing conditions to open up fractures and increase injectivity, was of $10 \mathrm{MPa}$ (Rutqvist 2012). The overpressure in the caprock is lower, but non-negligible, because even though the caprock has a very low permeability, the high overpressure in the reservoir induces flow of the resident brine across the caprock (Rutqvist et al. 2010; Chang et al. 2013; Vilarrasa \& Carrera 2015a).

The resulting overpressure is affected by nonisothermal effects (Fig. 5). In the reservoir, overpressure is slightly lower for cold $\mathrm{CO}_{2}$ injection because cold (liquid) $\mathrm{CO}_{2}$ is

Fig. 3. Temperature distribution after 5 years of injecting $\mathrm{CO}_{2}$ at $20^{\circ} \mathrm{C}$ through a horizontal well in a 20-m-thick reservoir.

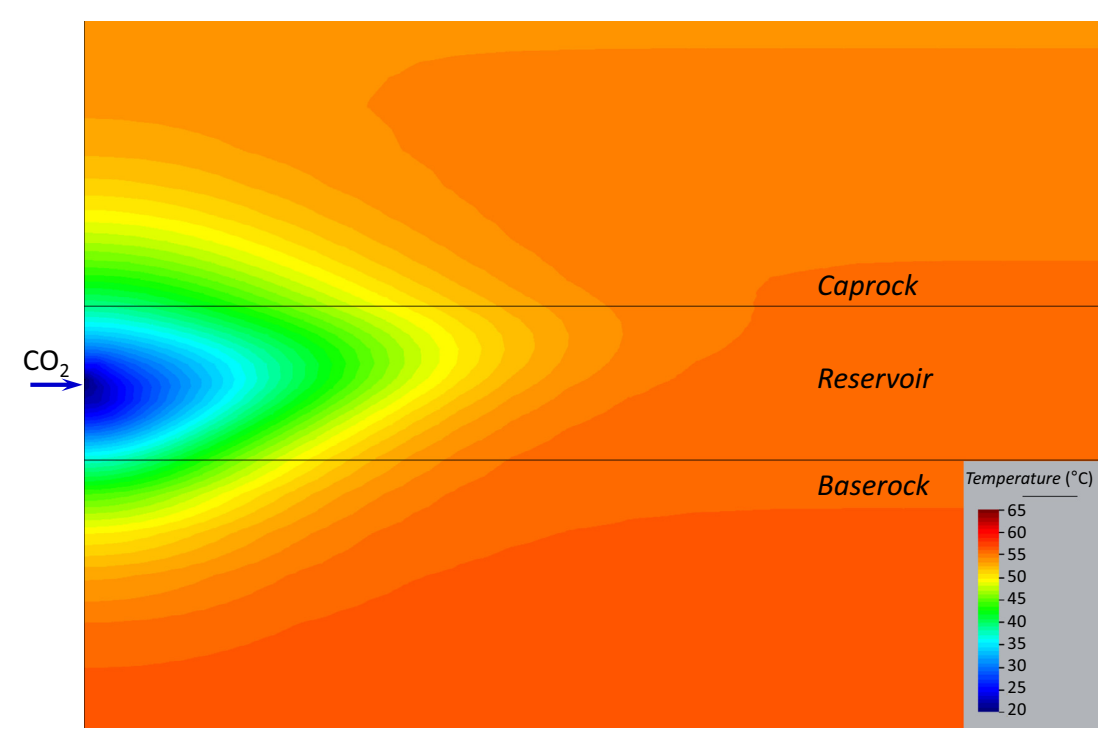




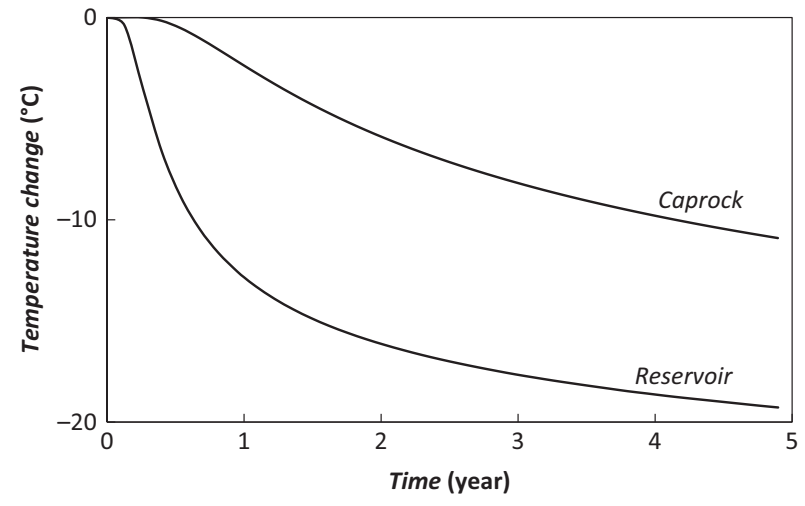

Fig. 4. Temperature change evolution when injecting $\mathrm{CO}_{2}$ that is $35^{\circ} \mathrm{C}$ colder than the rock (injected $10 \mathrm{~m}$ below the reservoir-caprock interface), measured at a distance from the injection well of $1 \mathrm{~m}$ both in the reservoir ( $2 \mathrm{~m}$ below the reservoir-caprock interface) and in the caprock ( $5 \mathrm{~m}$ above the reservoir-caprock interface).

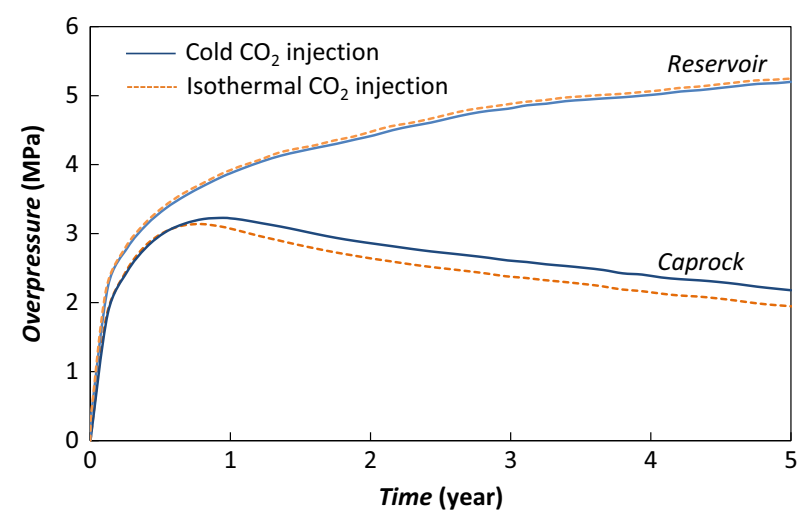

Fig. 5. Overpressure evolution in the reservoir and the caprock when injecting $\mathrm{CO}_{2}$ at $20^{\circ} \mathrm{C}$ (cold $\mathrm{CO}_{2}$ injection; continuous lines) and in thermal equilibrium with the storage formation (isothermal $\mathrm{CO}_{2}$ injection; dashed lines). Overpressure is measured at a distance from the injection well of $1 \mathrm{~m}$. In the reservoir, it is measured $2 \mathrm{~m}$ below the reservoir-caprock interface and in the caprock, $5 \mathrm{~m}$ above the reservoir-caprock interface.

denser than supercritical $\mathrm{CO}_{2}$ and therefore, the volumetric flow rate becomes smaller when injecting cold $\mathrm{CO}_{2}$. In the caprock, cooling induces changes in the volumetric strain. Since caprock porosity is very low, the contraction induced by cooling causes a small decrease of the caprock porosity (Vilarrasa et al. 2014). This porosity decrease causes a compression of the fluid that fills the pores, which induces a slight pressure build-up. Since the caprock has a low permeability, the resident brine cannot flow easily and the additional overpressure is not dissipated.

Figure 6 shows the total stress changes induced in a section that is not affected by cooling. Therefore, these changes are only due to overpressure and are very similar for injection of cold $\mathrm{CO}_{2}$ and $\mathrm{CO}_{2}$ in thermal equilibrium with the reservoir. The overpressure evolution in this section, which is placed $150 \mathrm{~m}$ away from the injection well,
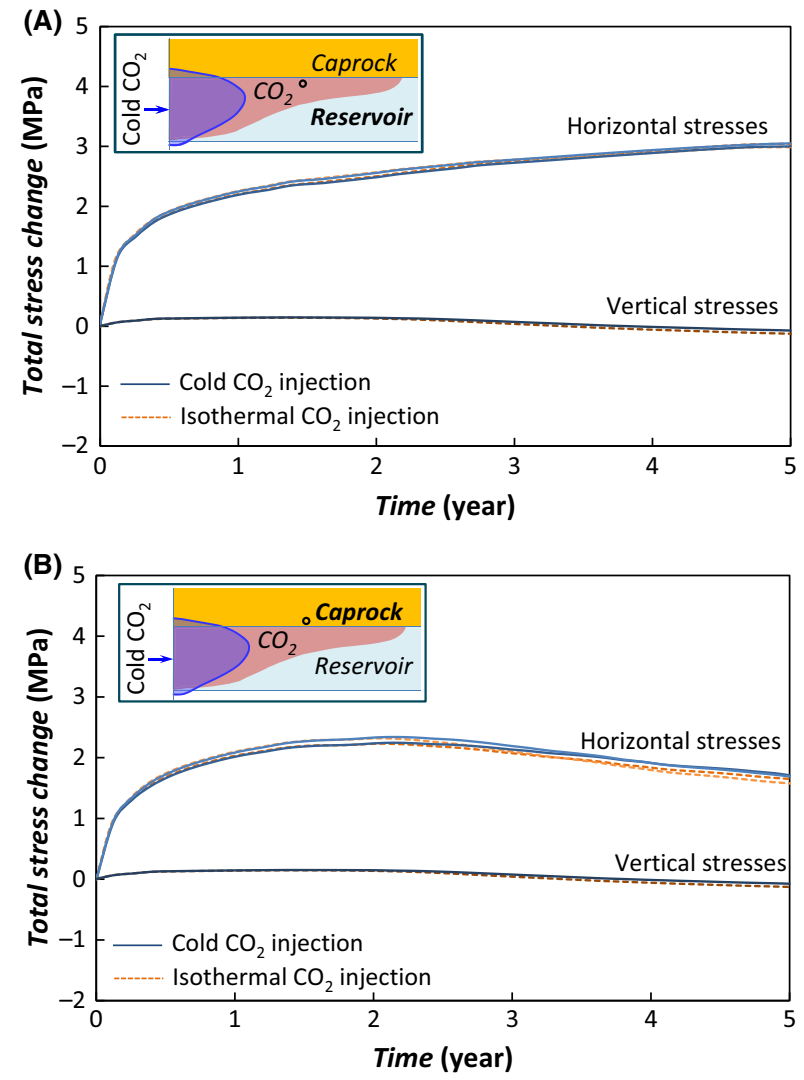

Fig. 6. Total stress evolution when injecting $\mathrm{CO}_{2}$ at $20^{\circ} \mathrm{C}$ (cold $\mathrm{CO}_{2}$ injection; continuous lines) and in thermal equilibrium with the storage formation (isothermal $\mathrm{CO}_{2}$ injection; dashed lines) ( $\mathrm{A}$ ) in the reservoir, $2 \mathrm{~m}$ below the reservoir-caprock interface and (B) in the caprock, $5 \mathrm{~m}$ above the reservoir-caprock interface. The measurements are made in a section placed $150 \mathrm{~m}$ away from the injection well. Cooling does not reach this section, so thermo-mechanical effects are negligible.

is similar to the one shown in Fig. 5 for a section placed close to the injection well. Overpressure induces an increment of the horizontal total stresses due to the lateral confinement, but the vertical stress remains practically constant because the rock can expand in this direction. The horizontal total stress increment is proportional to overpressure and very similar in all directions. Thus, the horizontal total stress increment is larger in the reservoir than in the caprock because overpressure is higher in the reservoir. This horizontal total stress increment can be estimated analytically assuming a thin, laterally extensive reservoir, in which there is no net horizontal strain, as (Hawkes et al. 2005)

$\Delta \sigma_{b}=\alpha_{b} \frac{1-2 v}{1-v} \Delta P$.

Simulation results yield a horizontal total stress increment in the reservoir of $3.13 \mathrm{MPa}$ and $2.99 \mathrm{MPa}$ in the maximum and minimum principal horizontal stresses, respectively, for an overpressure of $5.30 \mathrm{MPa}$. Taking into 
account that the Poisson ratio equals 0.3 and the Biot coefficient equals 1 , the horizontal total stress increment calculated analytically with Eq. (7) is $3.03 \mathrm{MPa}$, which is very similar to the mean stress increment predicted by the numerical model, that is $3.06 \mathrm{MPa}$. In the caprock, the horizontal total stress increment given by the model is slightly more anisotropic than in the reservoir and equals 1.28 MPa and 1.08 MPa in the maximum and the minimum horizontal stress, respectively, for an overpressure of 1.94 MPa. Using Eq. (7), the horizontal stress increment results in $1.11 \mathrm{MPa}$, which is slightly higher than the minimum horizontal stress increment predicted by the numerical model.

Figure 7 displays the total stress changes induced by both overpressure and cooling in a section close to the injection well and thus affected by cooling. Cooling induces a thermal stress reduction in all directions. Nevertheless, the magnitude of the induced thermal stresses is direction dependent due to different lateral confinement in
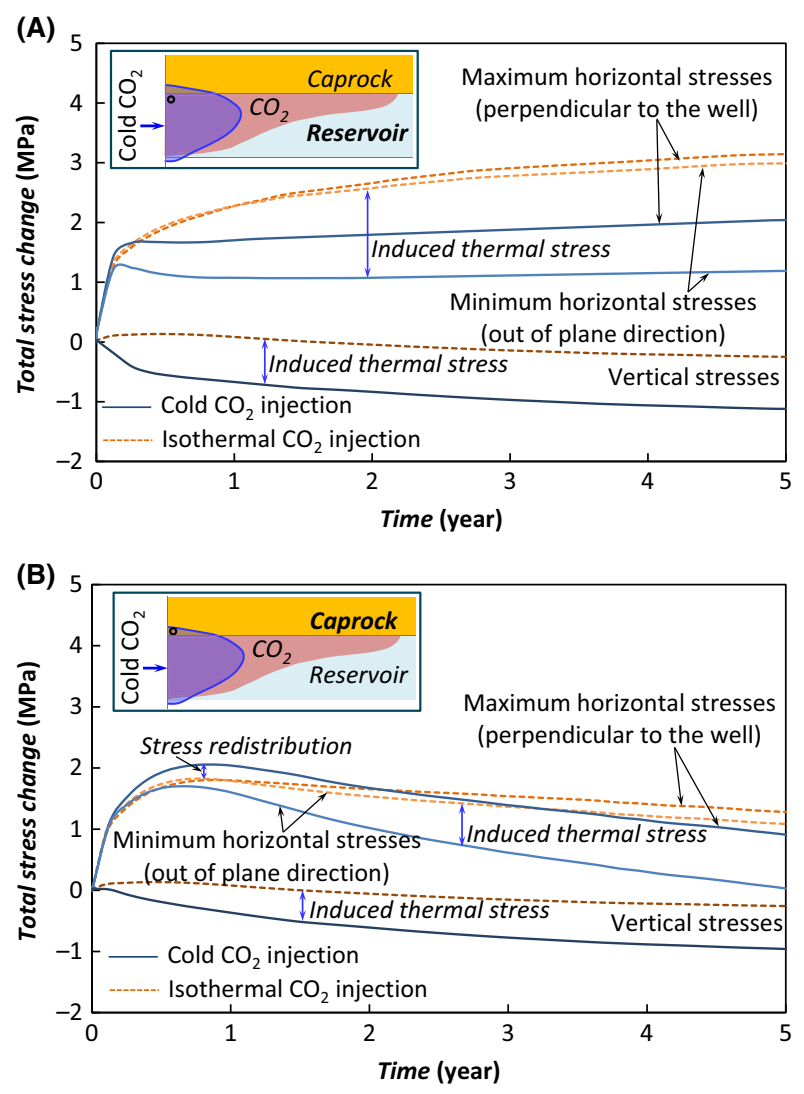

Fig. 7. Total stress evolution when injecting $\mathrm{CO}_{2}$ at $20^{\circ} \mathrm{C}$ (cold $\mathrm{CO}_{2}$ injection; continuous lines) and in thermal equilibrium with the storage formation (isothermal $\mathrm{CO}_{2}$ injection; dashed lines) in a section placed $1 \mathrm{~m}$ away from the injection well and, thus, affected by cooling $(A)$ in the reservoir, $2 \mathrm{~m}$ below the reservoir-caprock interface and (B) in the caprock, $5 \mathrm{~m}$ above the reservoir-caprock interface. The differences in the stress evolution between the cold $\mathrm{CO}_{2}$ injection and isothermal simulations are the induced thermal stresses. each direction. The largest induced thermal stress occurs in the out-of-plane direction because of the plane strain condition, which fixes the displacement to zero in this direction, that is parallel to the injection well. Thermal stresses can also be estimated analytically as (Segall \& Fitzgerald 1998)

$\Delta \sigma_{T}=K \alpha_{T} \Delta T$

where $K\left[\mathrm{M} \mathrm{L}^{-1} \mathrm{~T}^{-2}\right]$ is the bulk modulus. The simulated induced thermal stresses vary significantly in each principal stress. In the reservoir, a temperature change of $-19^{\circ} \mathrm{C}$ yields thermal stresses of $-0.87 \mathrm{MPa},-1.06 \mathrm{MPa}$ and $-1.76 \mathrm{MPa}$ in the vertical, maximum and minimum horizontal stresses, respectively. If the minimum horizontal stress is not taken into account, because the plane strain symmetry significantly affects the induced thermal stress, the mean induced thermal stress of the vertical and maximum horizontal stresses becomes $-0.97 \mathrm{MPa}$, which is very similar to the thermal stress of $-0.96 \mathrm{MPa}$ calculated using Eq. (8). In the caprock, the induced thermal stresses given by the numerical model are $-0.70 \mathrm{MPa},-0.36 \mathrm{MPa}$ and $-1.04 \mathrm{MPa}$ in the vertical, maximum and minimum horizontal stresses, respectively. Again, the mean induced thermal stress of the vertical and maximum horizontal stresses results in $-0.53 \mathrm{MPa}$, which is very similar to the thermal stress of $-0.54 \mathrm{MPa}$ calculated using Eq. (8).

The smallest induced thermal stress in the reservoir takes place in the vertical direction. This reduction in the vertical total stress inside the reservoir causes disequilibrium in the stress balance because the overburden on top of the reservoir remains constant. Thus, to satisfy the stress equilibrium and displacement compatibility, stress redistribution occurs in which the horizontal total stresses, especially the maximum one (perpendicular to the well), increase in the lower portion of the caprock (See Fig. 7B). This stress redistribution is more pronounced at the beginning of injection, but it progressively attenuates as the cooled region extends (Vilarrasa et al. 2014). Still, after 5 years of injection, it is still noticeable, as evidenced by the fact that the thermal stress reduction in the maximum horizontal stress is the lowest in the caprock. These stress changes have different implications on fracture stability, and thus on induced microseismicity, depending on the initial stress state, that is whether it is a normal faulting, strike slip or reverse faulting stress regime.

\section{Normal faulting stress regime}

Figure 8 illustrates the stress state, using Mohr circles, in a normal faulting stress regime, prior to injection and after 5 years of cold $\mathrm{CO}_{2}$ injection and injection of $\mathrm{CO}_{2}$ in thermal equilibrium with the reservoir, in the zone affected by cooling. In the reservoir (Fig. 8A), if we first focus on the isothermal case (HM circle), the effective stresses 

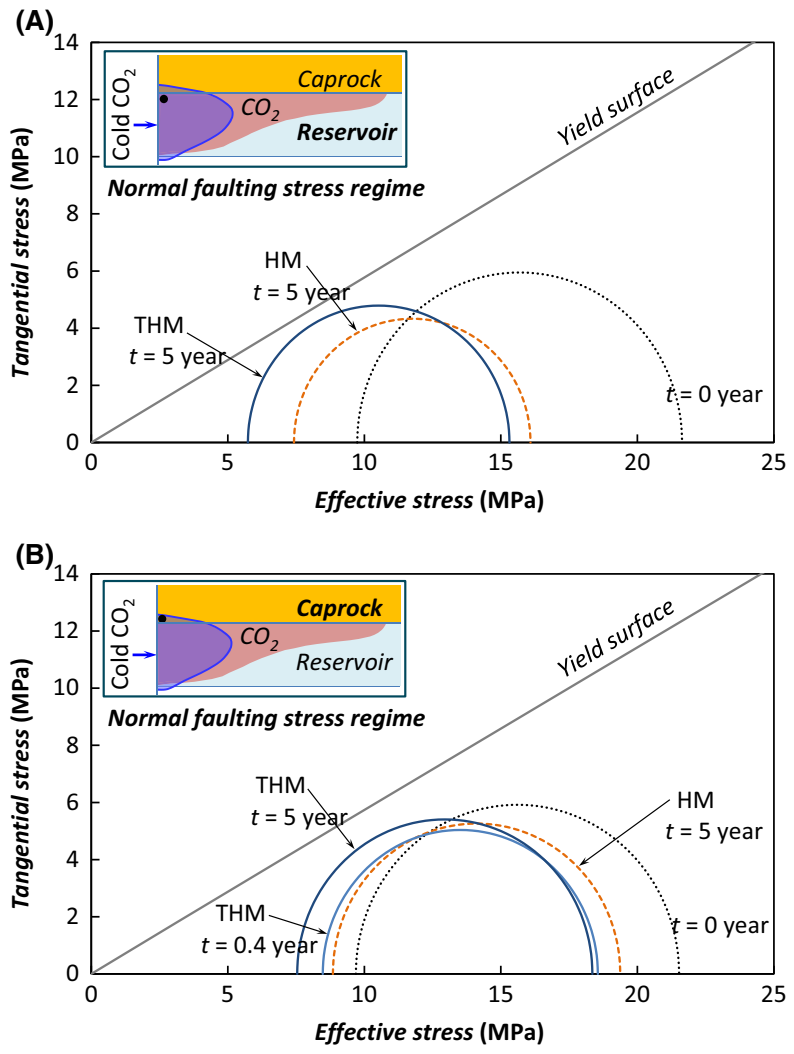

Fig. 8. Mohr circles in a normal faulting stress regime prior to injection and after 5 years of injecting $\mathrm{CO}_{2}$ at $20^{\circ} \mathrm{C}$ (THM circles) and $\mathrm{CO}_{2}$ in thermal equilibrium with the storage formation ( $\mathrm{HM}$ circles) measured $1 \mathrm{~m}$ away from the injection well (cooling takes place) (A) in the reservoir, $2 \mathrm{~m}$ below the reservoir-caprock interface and (B) in the caprock, $5 \mathrm{~m}$ above the reservoir-caprock interface.

decrease due to the induced overpressure (recall Fig. 5). However, the Mohr circle shrinks instead of being simply shifted towards the yield surface, which would have caused failure conditions. This shrinkage occurs due to the hydromechanical response of the porous media, in which an overpressure induces an increase in the horizontal total stresses (recall Fig. 6 and Eq. 7). Thus, if no cooling occurs, fractures remain stable because the Mohr circle does not approach the yield surface. In fact, the mobilized friction angle decreases slightly as overpressure increases in both the reservoir and the caprock, so fracture stability improves.

In contrast, cooling tends to induce fracture instability (THM circle). On the one hand, the thermal stress reduction brings the stress state closer to shear failure conditions. And on the other hand, the anisotropy in the induced thermal stresses causes an increase in the size of the Mohr circle because the minimum effective stress (horizontal stress) decreases more than the maximum effective stress (vertical stress; recall Fig. 7). In the simulated case, shear failure conditions are not reached in the reservoir, but the mobilized friction angle becomes $27^{\circ}$, which is close to the assumed friction angle of fractures, that is $30^{\circ}$. However, if the reservoir had been stiffer, that is higher Young's modulus (by a factor of two or more), or if the temperature drop had been larger (like next to the injection well), shear failure conditions would have been reached.

The stress redistribution that occurs in the lower portion of the caprock has a significant effect in a normal faulting stress regime. The increment in the horizontal total stresses offsets the induced thermal stress reduction in the horizontal direction, and thus, the Mohr circle shrinks at short times of injection, that is $<1$ year (Fig. 8B). However, induced thermal stresses become dominant for larger injection times, so the tightening of the caprock due to cooling vanishes after several months of cold $\mathrm{CO}_{2}$ injection. Still, the stress redistribution has some positive effect because the mobilized friction angle in the caprock remains lower than in the reservoir, reaching a mobilized friction angle of $24.7^{\circ}$ after 5 years of injection.

\section{Strike slip stress regime}

Figure 9 shows the Mohr circles in a strike slip stress regime prior to injection and after 5 years of injection of cold $\mathrm{CO}_{2}$ and $\mathrm{CO}_{2}$ in thermal equilibrium with the reservoir. When no cooling occurs (HM circles), the Mohr circle is shifted towards the yield surface because the maximum and the minimum principal effective stresses are both horizontal. Thus, the two horizontal stresses experience the same changes, which equal the overpressure (Fig. 5) minus the total stress change caused by overpressure (Fig. 6). Even though the decrease in these effective stresses is smaller than overpressure, the stress state becomes less stable than in a normal faulting stress regime because the size of the Mohr circle is maintained. The shifting of the Mohr circle occurs both in the reservoir and the caprock, but with a smaller magnitude in the caprock due to the lower overpressure. Thus, the caprock remains more stable than the reservoir, with a mobilized friction angle of $22.8^{\circ}$ compared to the $25.3^{\circ}$ in the reservoir.

When cooling occurs (THM circles), the Mohr circles, both in the reservoir and the caprock, are displaced towards the yield surface due to the thermal stress reduction. Furthermore, the Mohr circles increase in size, that is the deviatoric stress increases, because the stress reduction is larger in the minimum effective stress than in the maximum one. The combination of these two effects leads to shear failure conditions of a critically oriented fracture in the reservoir (Fig. 9A). The caprock remains more stable than the reservoir (mobilized friction angle of $25.9^{\circ}$ ), similarly as happens when no thermal effects occur, because of the lower overpressure and temperature drop. However, shear failure conditions, and thus microseismicity, may 
(A)

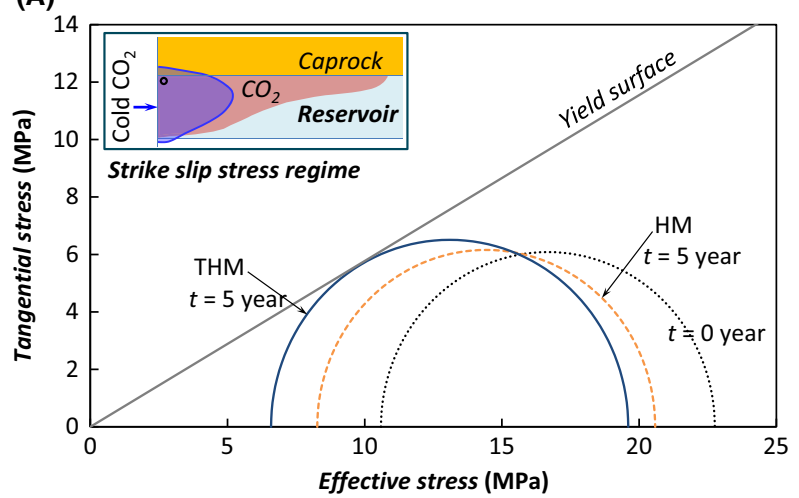

(B)

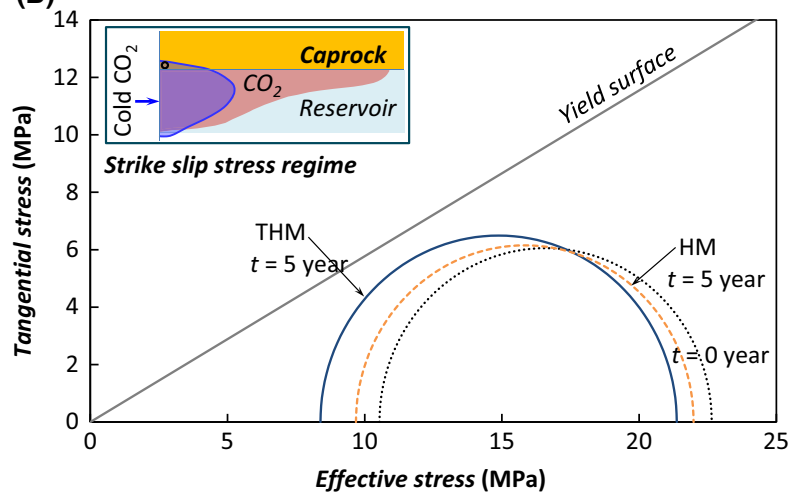

Fig. 9. Mohr circles in a strike slip stress regime prior to injection and after 5 years of injecting $\mathrm{CO}_{2}$ at $20^{\circ} \mathrm{C}$ (THM circles) and $\mathrm{CO}_{2}$ in thermal equilibrium with the storage formation (HM circles) measured $1 \mathrm{~m}$ away from the injection well (cooling takes place) (A) in the reservoir, $2 \mathrm{~m}$ below the reservoir-caprock interface and (B) in the caprock, $5 \mathrm{~m}$ above the reservoir-caprock interface.

occur in the caprock for a larger temperature contrast or a stiffer caprock, as occurred at In Salah, Algeria (Gor et al. 2013; Vilarrasa et al. 2015).

\section{Reverse faulting stress regime}

Figure 10 displays the stress state in a reverse faulting stress regime prior to injection and after 5 years of injecting cold $\mathrm{CO}_{2}$ and $\mathrm{CO}_{2}$ in thermal equilibrium with the storage formation. The coupled thermo-hydro-mechanical stress evolution is somewhat opposite to what happens in a normal faulting stress regime because, in this case, the maximum effective stress is horizontal and the minimum one is vertical. When only overpressure occurs (HM circles), the effective stresses decrease due to overpressure. But unlike a normal faulting stress regime, the Mohr circle increases in size because the vertical total stress remains practically constant, but the horizontal total stresses increase as a response to overpressure (Fig. 6). Thus, the Mohr circle approaches shear failure conditions. So contrary to a normal faulting stress regime, where the Mohr circle decreases in size and thus, stability improves slightly,
(A)

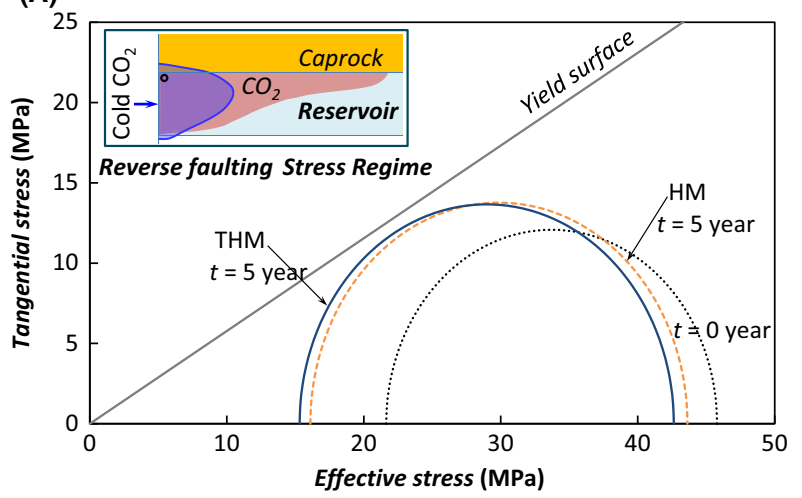

(B)

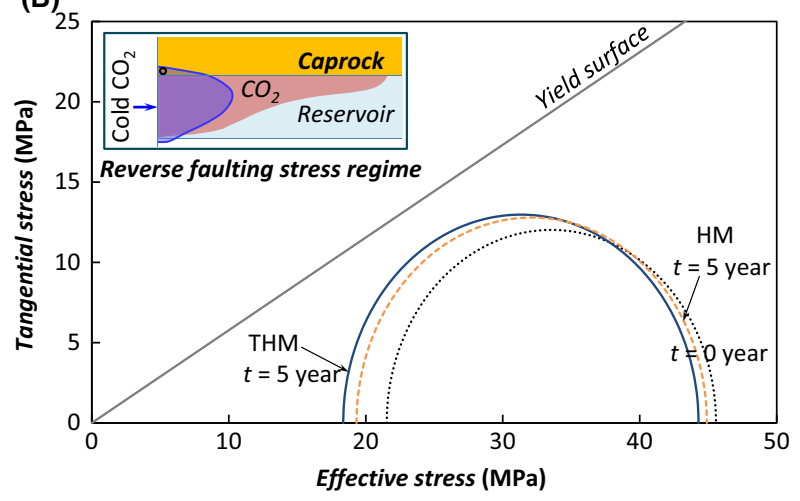

Fig. 10. Mohr circles in a reverse faulting stress regime prior to injection and after 5 years of injecting $\mathrm{CO}_{2}$ at $20^{\circ} \mathrm{C}$ (THM circles) and $\mathrm{CO}_{2}$ in thermal equilibrium with the storage formation ( $\mathrm{HM}$ circles) measured $1 \mathrm{~m}$ away from the injection well (cooling takes place) (A) in the reservoir, $2 \mathrm{~m}$ below the reservoir-caprock interface and (B) in the caprock, $5 \mathrm{~m}$ above the reservoir-caprock interface.

stability decreases significantly in a reverse faulting stress regime. This decrease in stability occurs both in the reservoir and the caprock, but the stability reduction is higher in the reservoir due to the higher overpressure.

The impact of thermo-mechanical effects is less significant in a reverse faulting than in the other stress regimes. This is because the induced thermal stresses are the same in all cases, but since the maximum effective stress in a reverse faulting stress regime is much larger than in the other stress regimes (roughly by a factor of 2 ), the relative change in effective stresses induced by cooling is smaller. Still, the thermal stress reduction brings the stress state slightly closer to the yield surface, so stability decreases. In the reservoir, the larger thermal stress reduction in the horizontal than in the vertical direction leads to a small reduction in the size of the Mohr circle, which limits the decrease in stability. In fact, the mobilized friction angle only increases from $27.4^{\circ}$ when only overpressure occurs to just $28.1^{\circ}$ when also cooling takes place. However, the size of the Mohr circle in the caprock increases because the increment of the horizontal total stress in the caprock caused by stress redistribution leads 
to a lower thermal stress reduction in the maximum (horizontal) than in the minimum (vertical) effective stress. Nevertheless, the decrease in stability caused by cooling of the caprock is relatively small (cooling causes an increase in the mobilized friction angle from $23.5^{\circ}$ to $\left.24.5^{\circ}\right)$.

\section{DISCUSSION}

Simulation results show that the initial stress state determines the effective stress path evolution, and thus fracture stability, when injecting cold $\mathrm{CO}_{2}$ in deep saline formations. Therefore, it is crucial to measure the stress state at least in the layers involved in $\mathrm{CO}_{2}$ storage, that is reservoir, caprock and baserock. Furthermore, performing a good thermo-hydro-mechanical characterization of these layers is also very important to accurately estimate the maximum sustainable injection pressure and the maximum temperature drop that can be carried out safely, that is without compromising caprock integrity and/or fault stability. Laboratory experiments of intact rock samples should be carried out to measure rock properties such as permeability, porosity, Young's modulus, Poisson ratio and thermal expansion coefficient. However, the presence of fractures in the field can modify the value of rock properties by one to three orders of magnitude with respect to those of the intact rock (e.g. Neuzil 1986; Verdon et al. 2011). Therefore, field tests are also necessary to determine rock properties at the scale of interest.

The least stable stress regime when injecting cold $\mathrm{CO}_{2}$ is a strike slip stress regime (Fig. 9). Since the maximum and the minimum effective stresses are both horizontal, the size of the Mohr circle is maintained because the two stresses undergo very similar total stress changes as a response to overpressure and temperature drop. Thus, the Mohr circle is shifted towards the yield surface and reaches failure conditions in the reservoir for the scenario simulated in this study. The critically oriented fractures that will first undergo shear are vertical fractures that form an angle with the maximum horizontal stress of $45^{\circ}-\sigma^{\prime} / 2$, where $\sigma^{\prime}[-]$ is the friction coefficient of fractures, which is usually assumed to be equal to $30^{\circ}$ (Byerlee 1978).

Shear failure of fractures may induce microseismicity, as occurred at In Salah (Oye et al. 2013), where around 9500 microseismic events were detected between 2009 and 2011 (Stork et al. 2015). Most of the microseismic events were located in or below the reservoir (Stork et al. 2015), which is consistent with our simulation results that show that the stress state becomes less stable in the reservoir than in the caprock (recall Fig. 9). Although most of the events were probably due to overpressure, because injection was performed at the fracturing pressure, the events close to the injection wells were probably due to cooling because the temperature difference between the injected $\mathrm{CO}_{2}$ and the reservoir was of $45^{\circ} \mathrm{C}$ (Bissell et al. 2011) and the rocks are stiff, with a Young's modulus in the order of $6 \mathrm{GPa}$ in the reservoir and $20 \mathrm{GPa}$ in the caprock (Rutqvist et al. 2010). Interestingly, there was no reported felt event during the whole $\mathrm{CO}_{2}$ injection between 2004 and 2011 (Rutqvist 2012).

If no cooling occurs, normal faulting is the most stable stress regime because the increase in the horizontal total stresses reduces the size of the Mohr circle, which offsets its displacement towards the yield surface caused by overpressure. In fact, the mobilized friction angle slightly decreases, so in spite of the effective stress reduction caused by overpressure, fracture stability improves. However, the thermal stresses induced in the cooled region around the injection well significantly reduce fracture stability, especially in the reservoir. Hence, cooling is the most likely mechanism to induce microseismicity in normal faulting stress regimes.

In contrast, reverse faulting is the least stable stress regime when only overpressure occurs because the increase in the horizontal total stresses causes an increase in the size of the Mohr circle. This increase significantly reduces fracture stability, which implies that induced microseismicity is likely to occur due to overpressure in reverse faulting stress regimes. As far as cooling is concerned, the high confining stress of this stress regime leads to a relatively small influence of thermo-mechanical effects on fracture stability. Still, when cooling occurs, a reverse faulting stress regime is less stable than a normal faulting stress regime, but more stable than a strike slip stress regime.

Shear slip of fractures is beneficial while it occurs within the reservoir because fracture roughness gives rise to dilatancy of fractures. And since dilatancy increases fracture aperture, permeability is enhanced. Actually, enhanced geothermal systems seek to induce shear slip of pre-existing fractures in high temperature $\left(\mathrm{T}>150^{\circ} \mathrm{C}\right)$ crystalline rocks to enhance permeability up to levels that permit circulating a sustained high flow rate of water $\left(>2001 \mathrm{sec}^{-1}\right)$ during 20-40 years to generate around 20 MWe. However, since the crystalline basement is usually critically stressed (Vilarrasa \& Carrera 2015a), the stimulation and production of enhanced geothermal systems is usually accompanied by felt induced seismicity (Majer et al. 2007), which in some cases has led to the closure of geothermal projects before they entered into operation, like at Basel, Switzerland (Häring et al. 2008).

Geologic carbon storage and other fluid injection operations, such as seasonal gas storage, compressed air energy storage and wastewater disposal, are usually performed in sedimentary formations. Unlike the critically stressed crystalline basement, sedimentary rocks are usually not critically stressed (Vilarrasa \& Carrera 2015a). Thus, there is some margin to induce overpressure and temperature drop without reaching failure conditions. However, knowing the initial stress state and how the changes in pressure and 
temperature will affect the effective stresses evolution is critical to perform a geomechanically stable fluid injection.

The simulation results of this study do not predict formation of hydraulic fractures because the minimum effective stress is always well above the tensile strength of the rock. However, stiffer rocks or larger cooling may induce a stress reduction that could cause tensile failure and thus formation of hydraulic fractures (Goodarzi et al. 2012, 2015). If hydraulic fractures propagate into the caprock, they may lead to $\mathrm{CO}_{2}$ leakage, which is a situation that should be avoided. An aspect that may favour maintaining caprock integrity is the horizontal stress heterogeneity that is usually found among different layers in sedimentary basins (Hergert et al. 2015). Caprocks are made of clayrich materials that are usually softer and more ductile than the clastic or carbonaceous reservoir rocks. As a result, the horizontal stress changes induced by tectonic movements are larger in the stiffer reservoirs than in the softer caprocks, as occurs in the Ohio River Valley, USA (Goodarzi et al. 2015), or the Molasse Basin, Switzerland (Hergert et al. 2015). Furthermore, pressure solution of limestone may also contribute to this stress heterogeneity (Gunzburger \& Cornet 2007). The lower horizontal stress changes in soft caprocks compared to the stiffer reservoirs lead to a stress state that is closer to isotropic conditions, that is lower deviatoric stress, in the caprocks than in the reservoirs. Thus, even though fractures may undergo shear slip in the reservoir, fracture instability is unlikely to propagate across the caprock due to the stress heterogeneity. The stress heterogeneity can also block the propagation of hydraulic fractures into the caprock in stress regimes where the minimum effective stress is not the vertical, that is in stress regimes different than reverse faulting (Goodarzi et al. 2015).

The findings of this study can be extended to the injection of other fluids. For instance, even though the injection of cold water will give rise to a somewhat different shape of the cooled region due to the buoyancy and the lower thermal conductivity of $\mathrm{CO}_{2}$, the effective stress changes will be similar in both cases. This similarity can be seen by comparing the results of Kim \& Hosseini (2015) for cold water injection with those of this study. Therefore, the implications of this study on how cooling affects fracture stability, and thus microseismicity, depending on the existing stress regime can be generalized to fluids different from $\mathrm{CO}_{2}$.

Overall, geologic carbon storage can be done safely. Microseismic activity can be limited to the reservoir, which will increase injectivity, and the caprock integrity and sealing capacity will still be maintained. To perform a safe injection, a precise characterization of the initial stress state in the reservoir, caprock and baserock is crucial because the effective stress evolution differs significantly depending on the stress regime. Furthermore, the thermo-hydro- mechanical properties of the rocks should be quantified at the field scale to estimate the induced total stress changes caused by overpressure (Eq. 7) and temperature drop (Eq. 8). Subsequently, numerical simulations should be performed to determine the maximum sustainable injection pressure and the maximum temperature drop. Finally, a proper pressure and temperature management should be carried out throughout fluid injection to ensure that neither caprock instability nor fault reactivate occurs.

\section{CONCLUSIONS}

We analyse the effect of the stress regime, that is normal faulting, strike slip or reverse faulting, on fault stability, and thus induced microseismicity, when injecting cold $\mathrm{CO}_{2}$ through a horizontal well in deep sedimentary formations. Cold $\mathrm{CO}_{2}$ injection forms a cold region around the injection well that propagates preferentially horizontally along the reservoir. Additionally, the lower portion of the caprock is cooled down by conduction. While the cold region extends several tens of metres, overpressure propagates over large distances and may affect faults in the far field. In the regions affected by overpressure, but not by cooling, the largest stability reduction occurs in reverse faulting stress regimes because the horizontal total stress increment that occurs as a response to overpressure results in an increase in the size of the Mohr circle. Fracture stability also decreases in strike slip stress regimes because the Mohr circle is shifted towards the yield surface. In strike slip stress regimes, the size of the Mohr circle remains practically constant because the maximum and minimum effective stresses are horizontal and, thus, undergo a similar reduction, which equals overpressure minus the increase in the horizontal total stress induced by overpressure. In contrast, fracture stability slightly improves in normal faulting stress regimes because even though the Mohr circle is displaced towards the yield surface due to overpressure, the increase in the horizontal total stresses reduces the size of the Mohr circle.

If cooling also occurs, fracture stability decreases due to the induced thermal stress reduction. The magnitude of the thermal stresses is proportional to the rock stiffness, the thermal expansion coefficient and the temperature change. Thus, microseismicity is likely to be induced by cooling in stiff rocks and for large temperature decrease. Strike slip stress regimes undergo the largest stability reduction induced by cooling when injecting through horizontal wells. Not only is the Mohr circle displaced towards the yield surface, but also its size increases because the thermal stress reduction is larger in the minimum than in the maximum horizontal effective stress due to the plane strain condition of the problem. The worsening in fracture stability in reverse faulting stress regimes is relatively small because the high confinement stress leads to a relatively 
small displacement of the Mohr circle towards the yield surface. As for normal faulting stress regimes, the thermal stress reduction in the minimum horizontal stress is larger than that in the vertical stress, which results in a displacement of the Mohr circle towards the yield surface and an increase in the size of the Mohr circle. Thus, induced microseismicity in normal faulting stress regimes is likely to be induced only by cooling.

To sum up, fracture stability, and thus induced microseismicity, is highly dependent on the stress regime. For this reason, measuring the stress state in the reservoir, caprock and baserock is very important to determine the maximum sustainable injection pressure and maximum temperature drop in each injection site. Once these thresholds are determined, a safe injection, without compromising the caprock integrity and sealing capacity, can be achieved by performing a proper pressure and temperature management.

\section{ACKNOWLEDGEMENTS}

V.V. acknowledges support from the 'EPFL Fellows' fellowship programme co-funded by Marie Curie, FP7 Grant agreement no. 291771.

\section{REFERENCES}

Bear J, ed. (1972) Dynamics of Fluids in Porous Media. Elsevier, New York.

Bissell RC, Vasco DW, Atbi M, Hamdani M, Okwelegbe M, Goldwater MH (2011) A full field simulation of the In Salah gas production and $\mathrm{CO}_{2}$ storage project using a coupled geomechanical and thermal fluid flow simulator. Energy Procedia, 4, 3290-7.

Byerlee JD (1978) Friction of rocks. Pure and Applied Geophysics, 116, 615-29.

Cappa F, Rutqvist J (2011) Impact of $\mathrm{CO}_{2}$ geological sequestration on the nucleation of earthquakes. Geophysical Research Letters, 38, L17313. doi:10.1029/2011GL048487.

Cesca S, Grigoli F, Heimann S, Gonzalez A, Buforn E, Maghsoudi S, Blanch E, Dahm T (2014) The 2013 SeptemberOctober seismic sequence offshore Spain: a case of seismicity triggered by gas injection? Geophysical Journal International, $198,941-53$

Chang KW, Hesse MA, Nicot JP (2013) Reduction of lateral pressure propagation due to dissipation into ambient mudrocks during geological carbon dioxide storage. Water Resources Research, 49, 2573-88.

Ellsworth WL (2013) Injection-induced earthquakes. Science, 341, 1225942 .

Evans KF, Zappone A, Kraft T, Deichmann N, Moia F (2012) A survey of the induced seismic responses to fluid injection in geothermal and $\mathrm{CO}_{2}$ reservoirs in Europe. Geothermics, 41, 3054 .

Goodarzi S, Settari A, Keith D (2012) Geomechanical modeling for $\mathrm{CO}_{2}$ storage in Nisku aquifer in Wabamun Lake area in Canada. International Journal of Greenhouse Gas Control, 10, 113-22.

Goodarzi S, Settari A, Zoback MD, Keith DW (2015) Optimization of a $\mathrm{CO}_{2}$ storage project based on thermal, geomechanical and induced fracturing effects. Journal of Petroleum Science and Engineering, 134, 49-59.

Gor GY, Elliot TR, Prévost JH (2013) Effects of thermal stresses on caprock integrity during $\mathrm{CO}_{2}$ storage. International Journal of Greenhouse Gas Control, 12, 300-9.

Gunzburger Y, Cornet FH (2007) Rheological characterization of a sedimentary formation from a stress profile inversion. Geophysical Journal International, 168, 402-18.

Häring MO, Schanz U, Ladner F, Dyer BC (2008) Characterisation of the Basel 1 enhanced geothermal system. Geothermics, 37, 469-95.

Hawkes CD, McLellan PJ, Bachu S (2005) Geomechanical factors affecting geological storage of $\mathrm{CO}_{2}$ in depleted oil and gas reservoirs. Journal of Canadian Petroleum Technology, 44, 5261

Hergert T, Heidbach O, Reiter K, Giber SB, Marschall P (2015) Stress field sensitivity analysis in a sedimentary sequence of the Alpine foreland, northern Switzerland. Solid Earth, 6, 533-52.

Hsieh PA, Bredehoeft JD (1981) A reservoir analysis of the Denver earthquakes: a case of induced seismicity. Journal of Geophysical Research, 86, 903-20.

IEAGHG (2013) Induced seismicity and its implications for $\mathrm{CO}_{2}$ storage risk. 2013/09, June 2013.

Juanes R, Hager BH, Herzog HJ (2012) No geologic evidence that seismicity causes fault leakage that would render large-scale carbon capture and storage unsuccessful. Proceedings of the National Academy of Sciences of the United States of America, 109, E3623.

Kim S, Hosseini SA (2015) Hydro-thermo-mechanical analysis during injection of cold fluid into a geologic formation. International Journal of Rock Mechanics and Mining Sciences, 77, 220-36.

Majer EL, Baria R, Stark M, Oates S, Bommer J, Smith B, Asanuma $\mathrm{H}$ (2007) Induced seismicity associated with enhanced geothermal systems. Geothermics, 36, 185-222.

Marschall P, Horseman S, Gimmi T (2005) Characterisation of gas transport properties of the Opalinus Clay, a potential host rock formation for radioactive waste disposal. Oil \& Gas Science and Technology, 60, 121-39.

Mazzoldi A, Rinaldi AP, Borgia A, Rutqvist J (2012) Induced seismicity within geologic carbon sequestration projects: maximum earthquake magnitude and leakage potential International Journal of Greenhouse Gas Control, 10, 434-42.

National Research Council (2013) Induced Seismicity Potential in Energy Technologies. National Acad. Press, Washington, DC.

Neuzil CE (1986) Groundwater flow in low-permeability environments. Water Resources Research, 22, 1163-95.

Nield DA, Bejan A (2006) Convection in Porous Media. Springer, New York.

Olivella S, Carrera J, Gens A, Alonso EE (1994) Non-isothermal multiphase flow of brine and gas through saline media. Transport In Porous Media, 15, 271-93.

Olivella S, Gens A, Carrera J, Alonso EE (1996) Numerical formulation for a simulator (CODE_BRIGHT) for the coupled analysis of saline media. Engineering Computations, $13,87-112$.

Oye V, Aker E, Daley TM, Kühn D, Bohloli B, Korneev V (2013) Microseismic monitoring and interpretation of injection data from the In Salah $\mathrm{CO}_{2}$ storage site (Krechba), Algeria. Energy Procedia, 37, 4191-8.

Paterson L, Lu M, Connell LD, Ennis-King J (2008) Numerical modeling of pressure and temperature profiles including phase transitions in carbon dioxide wells. SPE Annual Technical Conference and Exhibition, Denver, 21-24 September 2008. 
Phillips WS, Rutledge JT, House LS, Fehler MC (2002) Induced microearthquake patterns in hydrocarbon and geothermal reservoirs: six case studies. Pure and Applied Geophysics, 159, 345-69.

Preisig M, Prévost JH (2011) Coupled multi-phase thermoporomechanical effects. Case study: $\mathrm{CO}_{2}$ injection at In Salah, Algeria. International Journal of Greenhouse Gas Control, 5, 1055-64.

Rinaldi AP, Vilarrasa V, Rutqvist J, Cappa F (2015) Fault reactivation during $\mathrm{CO}_{2}$ sequestration: effects of well orientation on seismicity and leakage. Greenhouse Gases: Science and Technology, 5, 645-56.

Rutqvist J (2012) The geomechanics of $\mathrm{CO}_{2}$ storage in deep sedimentary formations. International Journal of Geotechnical and Geological Engineering, 30, 525-51.

Rutqvist J (2015) Fractured rock stress-permeability relationships from in situ data and effects of temperature and chemicalmechanical couplings. Geofluids, 15, 48-66.

Rutqvist J, Vasco DW, Myer L (2010) Coupled reservoirgeomechanical analysis of $\mathrm{CO}_{2}$ injection and ground deformations at In Salah, Algeria. International Journal of Greenhouse Gas Control, 4, 225-30.

Sánchez M, Shastri A, Le TMH (2014) Coupled hydromechanical analysis of an underground compressed air energy storage facility in sandstone. Géotechnique Letters, 4, 157-64.

Segall P, Fitzgerald SD (1998) A note on induced stress changes in hydrocarbon and geothermal reservoirs. Tectonophysics, 289, 117 28.

Segall P, Lu S (2015) Injection-induced seismicity: poroelastic and earthquake nucleation effects. Journal of Geophysical Research: Solid Earth, 120, 5082-103

de Simone S, Vilarrasa V, Carrera J, Alcolea A, Meier P (2013) Thermal coupling may control mechanical stability of geothermal reservoirs during cold water injection. Physics and Chemistry of the Earth, 64, 117-26.

Stork AL, Verdon JP, Kendall JM (2015) The microseismic response at the In Salah Carbon Capture and Storage (CCS) site. International Journal of Greenhouse Gas Control, 32, 159-71.
Verdon JP, Kendall J-M, White DJ, Angus DA (2011) Linking microseismic event observations with geomechanical models to minimise the risks of storing $\mathrm{CO}_{2}$ in geological formations. Earth and Planetary Science Letters, 305, 143-52.

Vilarrasa V, Carrera J (2015a) Geologic carbon storage is unlikely to trigger large earthquakes and reactivate faults through which $\mathrm{CO}_{2}$ could leak. Proceedings of the National Academy of Sciences of the United States of America, 112, 5938-43.

Vilarrasa V, Carrera J (2015b) Reply to Zoback and Gorelick: geologic carbon storage remains a safe strategy to significantly reduce $\mathrm{CO}_{2}$ emissions. Proceedings of the National Academy of Sciences of the United States of America, 112, E4511.

Vilarrasa V, Silva O, Carrera J, Olivella S (2013) Liquid $\mathrm{CO}_{2}$ injection for geological storage in deep saline aquifers. International Journal of Greenhouse Gas Control, 14, 84-96.

Vilarrasa V, Olivella S, Carrera J, Rutqvist J (2014) Long term impacts of cold $\mathrm{CO}_{2}$ injection on the caprock integrity. International Journal of Greenhouse Gas Control, 24, 1-13.

Vilarrasa V, Rutqvist J, Rinaldi AP (2015) Thermal and capillary effects on the caprock mechanical stability at In Salah, Algeria. Greenhouse Gases: Science and Technology, 5, 449-61.

Zhang Y, Person M, Rupp J, Ellett K, Celia MA, Gable CW, Bowen B, Evans J, Bandilla K, Mozley P, Dewers T, Elliot T (2013) Hydrogeologic controls on induced seismicity in crystalline basement rocks due to fluid injection into basal reservoirs. Groundwater, 51, 525-38.

Zoback MD, Gorelick SM (2012a) Earthquake triggering and large-scale geologic storage of carbon dioxide. Proceedings of the National Academy of Sciences of the United States of America, $109,10164-8$

Zoback MD, Gorelick SM (2012b) Reply to Juanes et al.: Evidence that earthquake triggering could render long-term carbon storage unsuccessful in many regions. Proceedings of the National Academy of Sciences of the United States of America, 109, E3624.

Zoback MD, Gorelick SM (2015) To prevent earthquake triggering, pressure changes due to $\mathrm{CO}_{2}$ injection need to be limited. Proceedings of the National Academy of Sciences of the United States of America, 112, E4510. 


\title{
GEOFLUIDS
}

\author{
Volume 16, Number 5, December 2016 \\ ISSN 1468-8115
}

\section{CONTENTS}

801 Injection-induced seismicity in Carbon and Emery Counties, central Utah M.R.M. Brown and M. Liu

813 Large-scale chemical stratification of fluids in the crust: hydraulic and chemical data from the geothermal research site Urach, Germany K. Bucher and I. Stober

826 The October 2008 Nový Kostel earthquake swarm and its gas geochemical precursor F.H. Weinlich, R. Gaždová, M. Teschner and J. Poggenburg

841 Quantitative analysis of $\mathrm{COH}$ fluids synthesized at HP-HT conditions: an optimized methodology to measure volatiles in experimental capsules

C. Tiraboschi, S. Tumiati, S. Recchia, F. Miozzi and S. Poli

856 Origin of dolomites in the Cambrian (upper 3rd-Furongian) formation, south-eastern Sichuan Basin, China M.C. Hou, W.J. Jiang, F.C. Xing, S.L. Xu, X.C. Liu and C. Xiao

877 Chemical evolution of metamorphic fluids in the Central Alps, Switzerland: insight from LA-ICPMS analysis of fluid inclusions K. Rauchenstein-Martinek, T. Wagner, M. Wälle, C.A. Heinrich and T. Arlt

909 Organic-inorganic rock-fluid interactions in stylolitic micro-environments of carbonate rocks: a FIB-TEM study combined with a hydrogeochemical modelling approach H. -M. Schulz, R. Wirth and A. Schreiber

925 Linked thermal convection of the basement and basinal fluids in formation of the unconformity-related uranium deposits in the Athabasca Basin, Saskatchewan, Canada A.A. Pek and V.I. Malkovsky

941 The role of the stress regime on microseismicity induced by overpressure and cooling in geologic carbon storage V. Vilarrasa

954 Numerical model of pore-pressure diffusion associated with the initiation of the 2010-2011 Guy-Greenbrier, Arkansas earthquakes P.O. Ogwari and S.P. Horton

971 Exploring the potential linkages between oil-field brine reinjection, crystalline basement permeability, and triggered seismicity for the Dagger Draw Oil field, southeastern New Mexico, USA, using hydrologic modeling Y. Zhang, S.S. Edel, J. Pepin, M. Person, R. Broadhead, J.P. Ortiz, S.L. Bilek, P. Mozley and J.P. Evans

988 Fluid chemistry in the Solitaire and Dodo hydrothermal fields of the Central Indian Ridge

S. Kawagucci, J. Miyazaki, T. Noguchi, K. Okamura, T. Shibuya, T. Watsuii, M. Nishizawa, H. Watanabe, K. Okino, N. Takahata, Y. Sano, K. Nakamura, A. Shuto, M. Abe, Y. Takaki, T. Nunoura, M. Koonjul, M. Singh, G. Beedessee, M. Khishma, V. Bhoyroo, D. Bissessur, L.S. Kumar, D. Marie, K. Tamaki and K. Takai

1006 Direct inversion of Young's and Poisson impedances for fluid discrimination Z. Zong and $\mathrm{X}$. Yin

1017 Bleached mudstone, iron concretions, and calcite veins: a natural analogue for the effects of reducing $\mathrm{CO}_{2}$-bearing fluids on migration and mineralization of iron, sealing properties, and composition of mudstone cap rocks

X.R. Ming, L. Liu, M. Yu, H.G. Bai, L. Yu, X.L. Peng and T.H. Yang

1043 Dry $\mathrm{CO}_{2}-\mathrm{CO}$ fluid as an important potential deep Earth solvent A.G. Simakin, T.P. Salova, R.I. Gabitov and S.I. Isaenko 